International

Medical Society

http://imedicalsociety.org

\title{
Is There an Association between Bariatric Surgery and Depresive Symptoms?
}

\begin{abstract}
Adilson Pontes da Rocha Filho1,2, Baibi Luren Ibiwari Horsfall', Isaac Belém Alves Lima1, Ismael Pereira do Nacimento1,2, Modesto Leite Rolim Neto1,3, Pedro Neto Lima de Oliveira1, Túllio Sampaio Pontes Grangeiro Teles 1,2
\end{abstract}

\section{Abstract}

Morbid obesity is a serious public health problem due to its effect in the long term morbity and mortality.The bariatric surgery came as an effective therapeutic arsenal to reduce the rate of this pathology. However, depressive symptoms and other psychopathologic disorders seem to occur in the post operation of these individuals. In this context, the present study aims at availiating if bariatric surgery for the reduction of the Body Mass Index (BMI) is associated to the permanence, worsening or even development of depressive symptoms in populations indicated for this procedure.

Morbid obesity is associated with increase in morbidity, mortality and represents an important health problem as its incidence increases worldwide. [1]. Individual experiences show that morbid obesity (BMIBody Mass Index greater than $40 \mathrm{Kg} / \mathrm{m}$ - (World Health Organization) is not only associated with systemic comorbidities but also to mental pathologies, like anxiety, depression and alimentary disorders. Bariatric surgery (BS) has been seen as one of the effiecient treatments for these cases. [2]

BS leads to a significant improvement in the depressive symptoms and a reduction in its prevalence. Evidences show a global reduction in about $65 \%$ of depression in individuals given to this trophical condition surgical treatment and such association appears to be linked to the "dose dependent" effect between the weight loss and the relief from detrimental mental symptoms. [3]
1 Universidade Federal do Cariri, Barbalha, Ceará, Brasil.

2 Programa de Residencia Médica em Cirurgia Geral, Universidade Federal do Cariri, Barbalha, Ceará, Brasil.

3 Docente pela Universidade Federal do Cariri, Barbalha, Ceará, Brasil.

Contact information:

Modesto Leite Rolim Netoa

”modestorolim@yahoo.com.br

Keywords

Bariatric Surgery; Depression. 
Though studies have related a post operational loss of weight with an improvement of the insatisfactory body image, some individuals have shown worries associated after the surgical procedure. These worries are connected to the increase in depressive symptoms and reduction of self esteem in these group of persons probably due to various factors like post surgicalweight gain, unreached expectations and the adoption of stresssful routines.

The prevalence of depression in the obese population is significant and more than half of the obese patients that need surgical treatment due to their conditions show criterias for instalation and development of psychiatric disorders. [3]

Ashleigh et al (2016) proposed a study in which 229 patients were analyzed, three (3) months after the surgery, all submitted to bariatric surgery. In the referred research, screening was made for the identification of comorbidities of psychopathologic nature as well as the attainment of results after avaliation of depressive state through appropriate rating scales. It was observed that patients submitted to bariatric surgery that had psychopathologic comorbidities or risk fators for these showed more probability in developing early worry about body image after the surgery [4].

From another perspective, Brandão et al, (2016) compared the efficacy and the impact of the types of bariatric surgery in the course of depression, systematic diseases and other mental disturnaces and obtained a result in which the pathology in question evoluted favourably after the surgery but only when the analysis was not controlled by the type of surgery, "the gastric by-pass" having a better prognostics, maybe because it caused greater weight loss, fewer side effects associated and more satisfaction [5].

Another perculiar aspect between the association of bariatric surgery and depression is in respect to the adolescent group. In this aspect, Kajsa Jarvholm et al, 2016 proposed a study in which 82 of 88 adolescents (with a mean age of 16.8 and 67\% females) were followed and availiated for mental health before and after an interval of time of 1-2 years after the realization of a bariatric surgery. It was noted that adolescentes with a pre operational mental health issues were predictive for a worsening of the symptoms, principally after the second year of surgery. The index for suicidal ideas in this group was greater when compared with the result of the adolescents without pre-operational psychopathologies [6].

An implementation of the surgical treatment for the cases of morbid obesity possesses natural systematic advantages in terms of a better organic prognostics, however, though the levels of satisfaction and good health appear to be associated after the procedure, there is a good part of the individuals that continue ou eve worsen depressive symptoms after bariatric intervention, including among the adolescent age group. [3, 4, 6]. However, authors agree with the fact that the systematic benefits of the procedure suppress not undergoing the surgery and that the psychologic manifestations should be treated concomitantly, through mental terapy [6]. Other lines of researches lack realizations especially those that analyze the wide range of effects of the bariatric surgery under the depressive optics, excluding the factors that can turn the data analysis ambiguous and incomplete.

\section{References}

1. Benediktsdottir, A., Halldorsson, T.I., Bragadottir, G.J., Gudmundsson, L., Ramel, A. Predictors of dropout and bariatric surgery in Icelandic morbidly obese female patients (2016) Obesity Research and Clinical Practice, 10 (1), pp. 63-69.

2. Taube-Schiff, M., Chaparro, M., Gougeon, L., Shakory, S., Weiland, M., Warwick, K., Plummer, C., Sockalingam, S. Examining Nutrition Knowledge of Bariatric Surgery Patients: What Happens to Dietary Knowledge over Time? (2016) Obesity Surgery, 26 (5), pp. 972-982. 
3. Switzer, N.J., Debru, E., Church, N., Mitchell, P., Gill, R. The Impact of Bariatric Surgery on Depression: a Review (2016) Current Cardiovascular Risk Reports, 10 (3), art. no. 12, pp. 1-5. 4. Pona, A.A., Heinberg, L.J., Lavery, M., Ben-Porath, Y.S., Rish, J.M. Psychological predictors of body image concerns 3 months after bariatric surgery (2016) Surgery for Obesity and Related Diseases, 12 (1), pp. 188-193.

5. Brandão, I., Pinho, A.M., Arrojado, F., Pinto-Bastos, A., Da Costa, J.M., Coelho, R., Calhau, C., Conceição, E. Type 2 diabetes mellitus, depression and eating disorders in patients submitted to bariatric surgery [Diabetes mellitus tipo 2, depressão e alterações do comportamento alimentar em doentes submetidos a cirurgia bariátrica] (2016) Acta Medica Portuguesa, 29 (3), pp. 176-181.

6. Järvholm, K., Karlsson, J., Olbers, T., Peltonen, M., Marcus, C., Dahlgren, J., Gronowitz, E., Johnsson, P., Flodmark, C.E. Characteristics of adolescents with poor mental health after bariatric surgery (2016) Surgery for Obesity and Related Diseases, . Article in Press.

Publish in International Archives of Medicine

International Archives of Medicine is an open access journal publishing articles encompassing all aspects of medical science and clinical practice. IAM is considered a megajournal with independent sections on all areas of medicine. IAM is a really international journal with authors and board members from all around the world. The journal is widely indexed and classified Q2 in category Medicine. 